\title{
The Lesbian Childbearing Experience: Assessing Developmental Tasks
}

\author{
Judith M. Wismont and Nancy E. Reame
}

Selected nursing theories about the childbearing experience are examined as they apply to the assessment of the pregnant lesbian couple. A review of the women's health literature suggests that the lesbian pregnancy experience is characterized by the use of donor insemination, social discrimination and a dependence on peer rather than family networks for social support. Based on these sociocultural constraints, the authors propose that the lesbian couple is faced with greater barriers than are heterosexual parents to achieving the developmental tasks of "safe passage" and acceptance by others of the pregnancy. Future research should document how a lesbian identity affects the pregnant woman's relationship with her mother, her partner's psychosocial development as a parent and the maternal-infant attachment process. Nursing guidelines for assessing parental role development are presented.

W ith the growing acceptance of nontraditional childbearing options, a variety of new clients has emerged to challenge traditional approaches to perinatal care. One such patient group is that of pregnant lesbian women and their female partner. In a survey of 1,921 self-identified, exclusively gay women, 691 $(36 \%)$ reported that they had considered having a child through donor insemination, and $589(31 \%)$ cited intercourse with either a cooperative or unsuspecting man as potential parenting options (Johnson, Smith \& Guenther, 1987).

Although there has been increased interest in lesbian parenting issues by feminist writers (Pies 1985; Pollack \& Vaughn, 1987), this client population has received limited attention in the health care literature (Good, 1976). Little is known about the effects of a homosexual identity and the use of donor insemination on the psychodynamics of maternal role development. For these individuals, given their sexual preference and special circumstances of conception, the attainment of parental identity may require a more complex perinatal adaptation than for traditional couples. The purpose of this paper is to aide practitioners in relating the developmental tasks of pregnancy to the lesbian childbearing experience. Selected nursing theories are examined as they apply to the pregnant lesbian couple, and nursing guidelines for assessing parental role development in this population are presented.

\section{Developmental Tasks of Pregnancy in the Lesbian Couple}

It is not clear to what extent maternity nursing theories about the traditional childbearing experience are clinically relevant in assessing development of the parental role in the lesbian couple. The psychosocial tasks described by Rubin (1984) include acceptance of pregnancy by self and others, safe passage, binding into the child and giving of oneself. Lederman (1984) documented the influence of the pregnant woman's relationships with her mother and spouse on the ability to achieve an optimum maternal identity. May (1982) identified three stages of spouse involvement during pregnancy whereby first-time fathers become invested in the parental role. Other nurse researchers have documented the fact that the quality of the prepregnant marital relationship is an important predictor of postpartum relations as well as the father's involvement with childbirth and childcare (Broom, 1983; Cronenwett, 1985; Ellis \& Hewat, 1985; Moore, 1983; Nicholson, Gist, Klein \& Stanley, 1983). None of these researchers, however, has explored the pregnancy experience within the context of a lesbian relationship. The following section describes the major developmental tasks of pregnancy (generated from nursing research) and their application to the assessment of the lesbian couple.

Acceptance of the pregnancy by self and others

Acceptance of the pregnancy refers to the conscious acknowledgment of "being pregnant" and its assimilation into ongoing relationships with the expectant woman's immediate and extended social group (Rubin, 1984). For the lesbian couple, the choice of donor insemination as the method of conception (as opposed to a heterosexual encounter) may foster acceptance of the pregnancy for both partners. It has been suggested that, because of the careful planning required for conception, there already exists a stronger commitment to parenting for the lesbian couple than for heterosexuals (Hill, 1987).

Health counselors typically encourage the nonbiologic parent to be an active participant in the insemination. Partner

JUDITH M. WISMONT, R.N., M.S., Rho, is Instructor and NANCY E. REAME, R.N., Ph.D., F.A.A.N., Lambda, is Associate Professor at the University of Michigan, Ann Arbor, Ml. Correspondence to School of Nursing, Room 4346, 400 N. Ingalls, Ann Arbor, Ml 48109-0482.

Accepted for publication January 5, 1989. 
involvement has included activities related to fertility assessment, semen collection, emotional support and the insemination procedure itself (Pies, 1985; Zook \& Hallenback, 1987). A number of insemination programs and sperm banks around the country provide services to the lesbian community either directly or indirectly through a health care provider (Parker, 1987).

Acceptance of the pregnancy by others may require careful negotiation on the part of the lesbian couple in order to ensure acceptance by family, the health care provider, the gay community and society in general. There may be disengagement by the couple from those within the social group who are not supportive of the parenting decision. Opposition from friends has been based on concerns regarding the sex role development of the child, decreased interest in political activism and personal motivation for choosing parenthood (Murphy, 1987; Pollack, 1987). This social dissolution is not unique to the lesbian experience but was described by Rubin (1984) as a phenomenon observed in many pregnant women who attempt to realign with more supportive social groups who share current interests and goals in childbearing. There is concern in the gay community that lesbian parents will favor friendships with heterosexual mothers, thus weakening their association with and subsequently the solidarity of the lesbian community (Hill, 1987; Pollack, 1987).

Lesbian couples who pursue parenting options face strong social sanctions from the health care system. Sexual orientation is not considered a contraindication for donor insemination (Strong \& Schinfeld, 1984), yet, Curie-Cohen, Luttrell \& Shapiro (1979) reported that of 471 physicians surveyed, only 9.5 percent reported having inseminated single women. The sexual preference of those women was not specified. Single persons of presumed heterosexual orientation are frequently excluded from consideration by adoption agencies in favor of married couples. It seems likely that acknowledged lesbians would be less apt to be judged acceptable by traditional health care personnel or agencies for either parenting option. In the one published study of these practices, only 2 percent of gay women who had considered parenting successfully achieved their goal: of these, 30 percent achieved a pregnancy through donor insemination; 9 percent became parents through adoption (Johnson et al., 1987).

The legal issues surrounding lesbian parenting may also interfere with the mother's ability to negotiate full social acceptance of her pregnancy. Because of societal and judicial homophobia, lesbian mothers fear custody loss (in cases of divorce), or the potential parental rights of the semen donor when his identity is known (Pollack, 1987).

Lesbian mothers can circumvent the issue of the legal rights of semen donors by using anonymous or multiple donors. As is the case for other single women, the last name on the child's birth certificate must be the same as that of the biologic mother. When the identity of the biologic father is known, lesbian women have been advised to withhold his name from the birth certificate to help prevent any further claim of parental rights (Pies, 1985).

Counselors are advising lesbian couples to establish legal contracts regarding the child's welfare in the event that a separation or death of one of the partners occurs (Hitchens, 1981; Lesbian Revisions Groups, 1984). The ability of the nonchildbearing partner to formulate a parental role may be hindered by the feeling that she has no legal ties or obliga- tions to the child. In many states, for the co-parent to adopt the child under current law, she must either first adopt the child's mother (i.e., her partner) or convince the biologic mother to transfer the parental rights to her (Pies, 1985; Polikoff, 1987).

\section{Safe passage}

Rubin's (1984) task of safe passage describes the pregnant woman's behaviors aimed at ensuring a healthy, safe birth for herself and her baby. For the lesbian couple, concerns with safe passage may begin with the insemination. Although detailed information about health screening criteria for donor selection is available (Lesbian Health Information Project, 1979; Pies, 1985), lesbian couples are questioning the practice of using semen donated by homosexual men because of the potential for the transmission of AIDS from this high-risk population (Loulan, 1987). The American Fertility Society now recommends the use of only frozen semen from donors who remain seronegative for the human immunodeficiency virus for three months following specimen collection (Peterson, Alexander \& Moghissi, 1988).

To ensure safe passage, the lesbian couple may feel especially invested in finding an accepting health care environment for childbearing care. Lesbian couples have reported difficulty finding health care providers who would support their concept of family (Zook \& Hallenback, 1987). They have felt inhibited about revealing their true relationship in childbirth preparation classes that were aimed at a heterosexual audience (Olesker \& Walsh, 1984).

In a survey of the health care needs of lesbian women, gynecologists were reported rarely to request sexual health information; 40 percent of the sample believed that physician knowledge about their sexual preference would hinder the quality of their medical care (Smith, Johnson \& Guenther, 1985). In a recent nursing study, 96 percent of lesbian subjects feared risk of harm ranging from reduced concern to actual infliction of pain if their health care provider were to know that they were gay (Stevens \& Hall, 1988). The fear of receiving less than optimal care because of heterosexual bias may be especially heightened for the lesbian couple at the time of delivery when parturient women are most vulnerable to fears of pain, loss of control and death (Lederman, 1984; Rubin, 1984).

\section{Binding into the child}

Rubin has observed that during the second trimester the psychoemotional investment shifts from the self to the wellbeing of the baby. Quickening facilitates this process of fetal attachment, which intensifies as the pregnancy proceeds to term.

An important component of the binding-in process is developing acceptance of the "real" baby versus the ideal baby that the woman fantasizes about throughout the pregnancy. Feminist writers predict that when the semen donor is anonymous, the inability to incorporate physical and personality characteristics of the father into the image of both the fantasy child and the real child hinders the maternal attachment process (Hubbard \& Sanford, 1984). Obtaining sperm from donors matched for physical characteristics of the lesbian co-parent has been proposed as a way to enhance parent-child identity formation (Parker, 1987).

It has been suggested by some gay activists that the sex of the child might be of more significance to a lesbian couple than to a heterosexual couple. (Langer, 1984; Lesbian Health 
Information Project, 1979). Homosexual women have been encouraged to use methods of fertilization that would increase their chances of conceiving a female child (Galana, 1978). In contrast, Pies (1985) proposed that most heterosexual women express a sex preference for their child and that it is a fallacy that lesbian mothers prefer female children. The feminist literature reflects at least an historical practice of social discrimination of lesbian mothers with male children (Goodman, Lakey, Lashof \& Thorne, 1983; Krieger, 1983; Lorde, 1987; Roberts, 1987). One can speculate that loss of support from the lesbian community would increase a lesbian mother's ambivalence to the pregnancy and subsequently make maternal attachment more difficult.

Breastfeeding has traditionally been advocated as a means for developing a more intense maternal attachment with the infant (Jelliffe \& Jelliffe, 1977). Health counselors for the lesbian community report that some nonbiological parents have considered this role for the purpose of "comfort" nursing. To the extent to which this practice occurs, one might predict that the binding-in process of these women to their partners' infants would be enhanced.

\section{Giving of oneself}

Rubin (1984) views childbirth as the act of giving of oneself-first to the child and then through the child to the partner, family and society as a whole. Throughout the pregnancy, the meaning of giving is clarified for the expectant mother through acts of self-gratification and the acceptance of gifts. The gift of self, however, is not without cost. This cost must be weighed against benefits anticipated from the experience. For the lesbian woman who often suffers social discrimination, the cost of the gift is especially great; and the gift becomes highly valued. As a result, the future child might be expected to take on a more significant role in meeting the woman's emotional needs. There is growing concern among child health specialists about the dangers of parental overinvolvement when babies become "too precious" because of special circumstances of birth (Williams, Berman \& Rose, 1987).

In the last trimester, the woman often experiences a sense of emotional and physical depletion-a feeling that she is no longer able to give any more of herself to the pregnancy. Rubin (1984) proposed that the level of emotional support available to the mother has an important influence on the degree of maternal attachment. According to health counselors of lesbian women, gay mothers generally expect a great deal of emotional support and nurturance from their partners; this includes acceptance by the partner of the body changes that accompany a pregnancy. It has been proposed that lesbian women better understand and therefore are more effective than are men in meeting their pregnant partner's increased need for nurturing activities such as cuddling, holding and fondling (Tolor \& Degrazia, 1976). Further research is needed to learn how pregnancy affects the sexual relationship of a lesbian couple.

\section{Maternal role modeling}

Lederman (1984) emphasized the woman's relationship with her mother as being an important developmental dimension of the maternal role. Reminiscing with her mother about childbearing and childrearing experiences serves to prepare the woman for her own mothering behaviors. Lederman has shown that the quality of this relationship may influence the labor and delivery experience. In studies of primiparious, married women, a poor relationship with the mother was found to be significantly related to prolonged labor (Lederman, Work \& McCann, 1979),

There is evidence to suggest that parents of homosexual individuals express dismay and guilt at the time of disclosure and experience an initial grief response (Griffin, Wirth \& Wirth, 1986). Depending on the level of resolution of this family crisis, the pregnancy of a lesbian woman can either foster a reconciliation or an alienation with the maternal grandmother. According to health counselors who work with the lesbian population, the family may vehemently disagree with a lesbian couple's choice to parent. It is not uncommon for these women to hide their homosexual relationship, preferring to appear to their families as unwed mothers (Pies, 1985; Robinson, 1985). For couples who disclose their lesbian relationship, families frequently become increasingly accepting as the pregnancy progresses (C. Carr, personal communication, 1986; Stern, 1980). In cases where a poor relationship persists, it is common for friends to take on the support and identity functions usually assumed by the biological family. According to health counselors, role models are frequently chosen from the lesbian community so that mothering behaviors are learned from a variety of individuals.

\section{Parental Role Development of the Co-Parent}

In the feminist literature, similarities have been drawn between the psychosocial experience of pregnancy for the lesbian co-parent and that of expectant fathers (Tortorilla, 1987). Although nursing research has recently gained new insights into the spouse's acquisition of the parental role (Bowen \& Miller, 1980; May, 1982; Weaver \& Cranley, 1983), further work is needed to confirm how well this developmental experience describes that for other nontraditional childbearing partners.

For the married, heterosexual couple, May (1982) identified three stages of paternal involvement during pregnancy that mark the transition to parenthood. The announcement phase, varying in length from a few hours to a few weeks, is characterized by joy and excitement for the father. In the moratorium phase, which lasts from a few days to several months, conscious thought about the pregnancy is put aside at a time when it is not yet physically evident. During the focusing phase, which begins between the twenty-fifth and thirtieth weeks of gestation and extends to the onset of labor, the father becomes ready to dwell on his attitudes and feelings about the pregnancy and to redefine himself as father.

The degree to which these developmental stages reflect the experience for gay co-parents is not known. May (1982) suggested that the portion of the spouse's emotional distancing that characterizes the moratorium phase of parental role attainment is the result in part of resentment of the woman's ability to conceive and bear a child. It is unlikely that this "womb-envy" would be experienced by a lesbian partner since she has made a cognitive decision not to carry the pregnancy and may choose to become the biological mother in subsequent pregnancies. Because the donor is a man and not in sexual competition with the partner, it is possible that lesbian couples would have less trouble dealing with the psychodynamics of insemination than do heterosexual couples. These women have reported a deep involvement with the pregnancy as a result of the love and empathy shared with their pregnant partners (Tortorilla, 1987); however, as with 
heterosexual couples, feelings of jealousy, ambivalence and doubt have been experienced by the nonchildbearing lesbian partner (Pies, 1985).

It could be argued that role expectations would be a significant issue for the lesbian partner, especially during the period after the birth of the child. Few formal models currently exist for validating this parental role. Difficulties have been described that center around conflicts about child care responsibilities and the more basic philosophical question of "Who's Mom?" (Pies, 1985; Clausen, 1987).

To some degree the ability of the couple to cope with parenting responsibilities is based on their ability to reorganize new support systems; former support systems such as childless friends may pull away after the birth. Because of the potential for scrutiny and alienation by the straight community, lesbian couples may feel a greater urgency to prevent dissolution of the partnership than do heterosexual couples. (Pies, 1985).

\section{Implications for Nursing Care}

Based on the major developmental tasks of pregnancy, Table 1 presents parenting role assessment guidelines for the nurse who develops a therapeutic relationship with the lesbian couple. These questions are intended not only to define the nature of the special circumstances surrounding the pregnancy but also to explore with the clients their concerns, desires and goals for achieving a positive childbearing experience.

Because of social discrimination and prejudicial attitudes, the lesbian childbearing couple is at risk for receiving less than optimal nursing care. The prenatal nurse specialist may fail to recognize adaptational responses of the nonbiologic parent to her partner's pregnancy. Although the importance of the labor partner has been well documented, lesbian couples may not be allowed the same level of intimacy in language and comfort measures as heterosexual partners in labor. In assessing the physical and psychosocial learning needs of the parturient woman, the postpartum nurse may not seek cues about sexual orientation. Despite these potential care deficits, nursing has been cited as the logical health profession to facilitate the lesbian patient's positive involvement in health care, as evidenced by its commitment to holistic health, advocacy for vulnerable cultural groups and an overwhelming majority of female providers (Stevens \& Hall, 1988).

Sexual health experts have long argued that clinicians who care for women need to assess their own beliefs and feelings about homosexuality and evaluate critically their willingness to provide care for the lesbian patient in a nonjudgmental manner (Olesker \& Walsh, 1984). For example, nurses can explore to what extent they harbor the subconscious fear of homosexuality as a contagious disease, a view that has been held responsible by some for the persistence of homophobia (Williamson, 1986).

Gay women feel hesitant to discuss their sexual preference with their care providers for fear it might affect negatively the quality of care they receive (Johnson, Guenther, Laube \& Keettel, 1981; Smith et al., 1985; Stevens \& Hall, 1988). To prevent a delay in prenatal care, nurses must respect the lesbian client's hesitancy to discuss her sexual practices yet be able to establish a relationship that fosters mutual acceptance. Recommendations for reducing sex orientation bias in the nursing assessment of women's health clients have been

TABLE 1. Nursing Guidelines for Assessing Adaptation to Parenting in the Lesbian Childbearing Couple.

\section{Developmental Task Assessment Question}

Acceptance of the pregnancy by others

Safe passage

Self-giving

Maternal role development

Co-parent role development
What is the impact of this pregnancy on the couple's family, social network and support system?

What is the legal relationship of the biologic father to this baby?

Does the partner intend to have a long term legal or social relationship as co-parent?

How was the pregnancy achieved? If by donor insemination, what was the partner's role?

Is the couple aware of the sperm donor's physical characteristics? Were they matched with the mother? the partner?

Was a sex selection method used with donor insemination? Is there a sex preference for the baby by the couple?

How will the couple's social network and support systems view the sex of the baby? What is the mother's image of the unborn baby? the partner's?

What health screening criteria were used for donor sperm selection?

Does the couple feel safe to disclose their relationship to the birth attendants?

How can the nurse assist in ensuring a positive labor and delivery experience for the couple?

What are the costs and benefits (emotional, economic, socio-legal) of this baby to the couple?

How does the partner replenish the pregnant woman's emotional and physical reserves?

Who will the mother use as a role model? How is the pregnant woman's mother involved with the pregnancy?

How is this pregnancy affecting the partner's life and relationship with the mother?

How does the partner plan to be involved in the pregnancy, birth and infant care?

What does the partner wish to be called by the child?

developed and may improve patient rapport (Williamson, 1986). The National Lesbian and Gay Health Foundation, Inc., of Washington, D.C., has developed a directory of health care providers who are sensitive to the needs of gay patients.

Health care professionals have been challenged to reduce their ignorance about the homosexual life-style in general and health concerns in particular (Johnson \& Palermo, 1984). One of the most commonly held myths about homosexual men and women is that they are unfit to parent and would be likely to foster homosexual behavior in their own children. It is estimated that there are as many as 1.5 million lesbian mothers in the United States (Hoeffer, 1981). Research over the last 20 years suggests that parental homosexuality has no effect on the sexual role development of children; children of 
lesbian mothers are no more likely to become homosexual than are children of single heterosexual mothers (Hoeffer, 1981; Pollack, 1987).

In summary, some underlying assumptions of maternalchild nursing theories may need to be re-examined in light of the lesbian experience. Because of the lack of societal acceptance of this life-style, the resulting dependence on social rather than family networks and the use of donor insemination, a pregnant lesbian couple may be faced with greater barriers than are heterosexual parents to achieving safe passage and acceptance of the pregnancy by others. Future research should document how a lesbian identity affects the pregnant woman's relationship with her mother, her partner's psychosocial development as a parent and the maternalinfant attachment process. 8

\section{References}

Bowen, S., \& Miller, B. (1980). Paternal attachment behavior as related to presence with delivery and preparenthood classes: a pilot study. Nursing Research, 29(5), $307-311$.

Broom, B. (1983). Consensus about the marital relationship during transition to parenthood. Nursing Research, 33(4), 223-228.

Clausen, J. (1987). To live outside the law you must be honest: A flommy look at lesbian parenting. In S. Pollack \& J. Vaughn (Eds.), Politics of the heart: A lesbian parenting anthology (pp. 333-342). Ithaca, NY: Firebrand Books.

Cronenwett, L. R. (1985). Network structure, social support and the psychological outcomes of pregnancy. Nursing Research, 34(2), 93-99.

Curie-Cohen, M., Luttrell, L., \& Shapiro, S. (1979). Current practice of artificial insemination by donor in the United States. New England Journal of Medicine, 300(11), 585-590.

Ellis, D., \& Hewat, R. (1985). Mothers' postpartum perceptions of spousal relationships. Journal of Obstetrics, Gynecologic and Neonatal Nursing, 14(2), 140-146.

Galana, L. (1978). Radical reproduction X without $Y$. In G. Covina \& L. Galana (Eds.), The lesbian reader (pp. 122-137). Berkeley, CA: Barn Owl Books.

Good, R. S. (1976). The gynecologist and the lesbian. Clinical Obstetrics \& Gynecology, 19(2), 473-482.

Goodman, G., Lakey, G., Lashof, J , \& Thorne, E. (1983). No turning back: Lesbian \& gay liberation for the 80's. Philadelphia, PA: New Society Publishers.

Griffin, C., Wirth, M., \& Wirth, A., (1986). Beyond Acceptance: Parents of lesbians and gays talk about their experiences. New Jersey: Prentice Hall, Inc.

Hill, K. (1987). Mothers by insemination: Interviews. In S. Pollack \& J. Vaughn (Eds.), Politics of the heart: A lesbian parenting anthology (pp. 111-119). Ithaca, NY: Firebrand Books.

Hitchens, D. J (1981) Lesbians choosing motherhood: Legal issues in donor insemination. San Francisco, CA: Lesbian Rights Project.

Hoeffer, B. (1981). Children's acquisition of sex role behavior in lesbian-mother families. American Journal of Orthopsychiatry, 51(7), 536-544.

Hubbard, R., \& Sanford, W. (1984). New reproductive technologies. In The Boston Woman's Health Book Collective (Eds), The new our bodies, ourselves, (pp. 317-324). New York: Simon \& Schuster, Inc.

Jelliffe, D., \& Jelliffe, E. (1977). Current concepts in nutrition: Breast is best-Modern meanings. New England Journal of Medicine, 297(17), 912-915.

Johnson, S. R., Guenther, S. M., Laube, D. W., \& Keettel, W. C. (1981). Factors influencing lesbian gynecologic care: A preliminary study. American Journal of Obstetrics and Gynecology, 140(1), 20-28.

Johnson, S. R., \& Palermo, J. L. (1984). Gynecologic care for the lesbian. Clinical Obstetrics and Gynecology, 27(3), 724-730.

Johnson, S. R., Smith, E. M., \& Guenther, S. M. (1987). Parenting desires among bisexual women and lesbians. Journal of Reproductive Medicine, 32(3), 198-200.

Krieger, S. (1983). The mirror dance: Identity in a women's community. Philadelphia, PA: Temple University Press.

Langer, N. (1984, November 3). Mothers by choice. Gay Community News.

Lederman, R., Lederman, E., Work, B., \& McCann, D. (1979). Relationship of psychological factors in pregnancy to progress in labor. Nursing Research, 28(2), 94-97.

Lederman, R. P. (1984). Psychosocial adaptation in pregnancy: Assessment of seven dimensions of maternal development. Englewood Cliffs, NJ: Prentice-Hall.

Lesbian Health Information Project (1979). Artificial insemination: An alternative conception. San Francisco: San Francisco Women's Centers.

Lesbians Revisions Groups (1984). Loving women: Lesbian life and relationships. In The Boston Women's Health Collectives (Eds.), The new our bodies, ourselves (pp. 141, 163). New York: Simon \& Schuster, Inc.
Lorde, A. (1987). Man child: A black lesbian-feminist's response. In S. Pollack \& J. Vaughn (Eds.), Politics of the heart: A lesbian parenting anthology (pp. 220-226). Ithaca, NY: Firebrand Books.

Loulan, J. (1987). Lesbian passion: Loving ourselves and each other. San Francisco: Spinsters/Aunt Lute.

May, K. A. (1982). Three phases of father involvement in pregnancy. Nursing Research, 31(6), 337-342.

Moore, D. (1983). Prepared childbirth and marital satisfaction during antepartum and postpartum periods. Nursing Research, 32(2), 73-79.

Murphy, M. (1987). And baby makes two. In S. Pollack \& J. Vaughn (Eds.), Politics of the heart: A lesbian parenting anthology (pp. 125-127). Ithaca, NY: Firebrand Books.

Nicholson, J., Gist, N., Klein, R., \& Stanley, K. (1983). Outcomes of father involvement in pregriancy and birth. Birth, 10(1), 5-9.

Olesker, E., \& Walsh, L. V. (1984). Childbearing among lesbians: Are we meeting their needs? Journal of Nurse-Midwifery, 29(5), 322-329.

Parker, P. (1987). Gay parenting, or, look out, Anita. In S. Pollack \& J. Vaughn (Eds.), Politics of the heart: A lesbian parenting anthology (pp. 94-99). Ithaca, NY: Firebrand Books

Peterson, E., Alexander, N., \& Moghissi, K. (1988). A.I.D. and AIDS: Too close for comfort. Fertility and Sterility, $49(2), 209-210$

Pies, C. (1985). Considering parenthood: A workbook for lesbians. San Francisco: Spinster's Ink.

Polikoff, N. D. (1987). Lesbian mothers, lesbian families: Legal obstacles, legal challenges. In S. Pollack \& J. Vaughn (Eds.), Politics of the heart: A lesbian parenting anthology (pp. 325-332). Ithaca, NY: Firebrand Books.

Pollack, S. (1987). Lesbian mothers: A lesbian-feminist perspective on research. In S. Pollack \& J. Vaughn (Eds.), Politics of the heart: A lesbian parenting anthology (pp. 316-324). Ithaca, NY: Firebrand Books.

Pollack, S., \& Vaughn, J. (Eds.) (1987). Politics of the heart: A lesbian parenting anthology. Ithaca, NY: Firebrand Books.

Roberts, R.K. (1987). A process of naming. In S. Pollack \& J. Vaughn (Eds.), Politics of the heart: A lesbian parenting handbook (pp. 149-151). Ithaca, NY: Firebrand Books.

Robinson, S. (1985). Having a baby without a man. New York: Simon \& Schuster, Inc.

Rubin, R. (1984). Maternal identity and the maternal experience. New York: Springer Publishing Co.

Smith, E. M., Johnson, S. R., \& Guenther, S. M. (1985). Health care attitudes and experiences during gynecologic care among lesbians and bisexuals. American Journal of Public Health, 75(9), 1085-1087.

Stern, S. (1980, Summer). Lesbian insemination. The Co Evolution Quarterly.

Stevens, P., \& Hall, J. (1988). Stigma, health beliefs and experiences with health care in lesbian women. Image: Journal of Nursing Scholarship, 20(2), 69-73.

Strong, C., \& Schinfeld, J. S. (1984). The single woman and artificial insemination by donor. Journal of Reproductive Medicine, 29(5), 293-299.

Tolor, A., \& Degrazia P. (1976). Sexual attitudes and behavior patterns during and following pregnancy. Archives of Sexual Behavior, 5, 539-551.

Tortorilla, T. (1987). On a creative edge. In S. Pollack \& J. Vaughn (Eds.), Politics of the heart: A lesbian parenting anthology (pp. 168-174). Ithaca, NY: Firebrand Books.

Weaver, R. H., \& Cranley, M. S. (1983). An exploration of paternal fetal attachment behavior. Nursing Research, 32(2), 68-72.

Willians, L. H., Berman, H. S., \& Rose, L. (1987). The too precious child. New York: Athenum Press.

Williamson, M. (1986). Lesbianism. In J. Griffith-Kenney (Ed.), Contemporary women's health: A nursing advocacy approach (pp. 279-296). Menlo Park, CA: Addison-Wesley Publishing Co.

Zook, N., \& Hallenback, R. (1987). Lesbian coparenting: Creating connections. In S. Pollack \& J. Vaughn (Eds.), Politics of the heart: A lesbian parenting anthology (pp. 89-93). Ithaca, NY; Firebrand Books.

\section{SOURCES - RESOURCES}

Cherm Ames-To complete a collection of the Cherry Ames book series, I am eager to buy any of the following:

Cherry Ames, Senior Nurse; Veterans Nurse; Visiting Nurse; Cruise Nurse; At Spencer; Mountaineer Nurse; Clinic Nurse; Dude Ranch Nurse; Department Store Nurse; Camp Nurse; Island Nurse; Staff Nurse. Theresa Stephany, RN, C, MS, 4606 Canary Drive, Pleasanton, CA 94566. Call collect (415) $462-7478$.

SOURCES - RESOURCES 